\title{
Efectos de la renovación urbana sobre la calidad de vida y perspectivas de relocalización residencial de habitantes centrales y pericentrales del Área Metropolitana del Gran Santiago
}

Ernesto López-Morales*. Universidad de Chile, Santiago, Chile. Camilo Arriagada-Luco. Universidad de Chile, Santiago, Chile. Ivo Gasic-Klett. Universidad Alberto Hurtado, Santiago, Chile. Daniel Meza-Corvalán. Universidad Federal de Río de Janeiro, Río de Janeiro, Brasil.

RESUMEN | Con base en una encuesta a 746 hogares residentes originales en seis zonas de renovación urbana en altura en Santiago de Chile, se analizan cuantitativamente percepciones (mayormente negativas) de los efectos de la construcción en altura sobre el medioambiente barrial, bienes públicos y privados atraídos, y valorización/desvalorización de entornos y propiedades residenciales, junto con las razones percibidas para esto último. Asimismo, a partir de una correlación de precios de suelo pagados durante el periodo 2000-2012 y de precios de departamentos nuevos ofrecidos en las zonas, observamos que cerca de la mitad de la población original residente no recibiría un precio de suelo suficiente para adquirir vivienda nueva y relocalizar en la misma zona a los integrantes de su hogar. Estos resultados muestran la alta necesidad de ampliar y mejorar la regulación de las externalidades sociales y económicas del mercado de renovación urbana en Santiago.

PALABRAS CLAVE | renovación urbana, encuesta a vecinos, exclusión residencial.

ABSTRACT | Based on a survey with 746 original households residents in six urban renewal areas in the heights of Santiago, Chile, the perceptions are quantified (mainly negative) of the effects of the high-rise construction on the local built environments, public and private goods attracted, valuation/devaluation of the neighborhood and existing residences, joint the reasons perceived for this latter. Furthermore, based on a correlation between the land prices paid by the period 2000-2012 and the sales prices of new apartments offered in these areas, we notice that almost half of the original residence population will not receive a land price enough to buy a new residence and to relocate their families in the same area. These results show the highly need to expand and improve the law of the social and economics externalities of the urban renewal market in Santiago.

KEYWORDs | urban renewal, survey to residents, residential exclusion.

Recibido el 25 de marzo de 2014, aprobado el 28 de noviembre de 2014

E-mail: Ernesto López-Morales, elopez@uchilefau.cl| Camilo Arriagada-Luco, carriagadal@uchilefau.cl| Ivo Gasic-Klett, ivogasick@gmail.

com | Daniel Meza-Corvalán,dmeza@uchilefau.cl

${ }^{*}$ Investigador Asociado CONICYT/FONDAP/15130009 


\section{Introducción}

El desarrollo urbano posterior al año 2000 en América del Norte, y especialmente del Sur, reporta una ralentización del patrón centrífugo residencial con un regreso de población y actividades comerciales al centro de la ciudad, fuertes desarrollos inmobiliarios en forma de renovación urbana en altura y altos niveles de aglomeración en espacios centrales (Borsdorf \& Hidalgo, 2013). En la comuna de Santiago, en el corazón del Área Metropolitana del Gran Santiago (AMGs), este proceso ha sido inédito por su escala y masividad, registrando la construcción de 100.000 viviendas aproximadamente en el lapso 2002-2011 ${ }^{1}$ para una población metropolitana de 6,5 millones, revirtiendo así la tendencia anterior de varias décadas de despoblamiento e incluso pérdida de viviendas. Ello no implica necesariamente que asistamos al fin de la suburbanización y contraurbanización en Chile, ya que aún un número importante de población sigue aspirando a vivir en modalidad de vivienda aislada suburbana, aunque el número de permisos de edificación en zonas periféricas metropolitanas de Santiago ha sido decreciente desde el año 1997 (López-Morales, Gasic \& Meza, 2012).

La masiva llegada de nuevas viviendas en condominios verticales a los centros ha sido estudiada por algunos autores desde el prisma de las nuevas tipologías residenciales y nuevos habitantes (Contreras, 2011; Inzulza-Contardo, 2011; Schlack \& Turnbull, 2011). Sin embargo, menor profundidad analítica ha recibido el estudio de los efectos sobre los barrios y la calidad de vida de los residentes antiguos, así como los indicios de saturación y externalidades que ha generado la densificación por crecimiento en altura. Poco se ha dicho en Chile también sobre el real aporte del mercado de renovación urbana en altura, en términos de atracción de bienes públicos a los barrios, y sobre todo respecto de la magnitud de la apropiación privada de plusvalías derivadas de obras públicas históricas y cambios de normas urbanísticas en zonas centrales, tema que ha sido profusamente abordado para otros casos latinoamericanos bajo la figura de land value capture (Smolka, 2013).

Esta preponderancia de un modelo de producción residencial en el centro y pericentro que, en el AMGs y desde 2008, supera al modelo de suburbanización, tanto en número de viviendas como en superficie nueva construida, también da tintes de presión de reemplazo de población de bajos ingresos, a través de modalidades de compraventa de suelo que en muchos casos devalúan el precio de pago por ese suelo, en perjuicio de residentes propietarios. Asimismo, López-Morales et al. (2012) muestran que entre los años 2000 y 2010, Santiago experimentó en sus once comunas central y pericentrales un incremento promedio notorio en el precio de venta de las unidades residenciales nuevas construidas, mayormente en altura, desde 1.100 a 1.500 uf, lo que refleja una elitización de sus mercados residenciales locales, con reducción del tamaño promedio de los departamentos, de 70 a $50 \mathrm{~m}^{2}$. Ello ha restringido la demanda a hogares pequeños, generalmente jóvenes, con capacidad de pago y/o endeudamiento bancario y, como indica Contreras (2011), con preferencia por activos culturales atractivos y diversos, situados en el centro. Esta tendencia se

Según datos de censos y precenso del ine. 
ha visto acompañada por una gestión municipal activa de los planes reguladores locales como oferta de "constructibilidad" al mercado, pero también por un fuerte rechazo a esta modalidad por parte de los residentes antiguos, que ha decantado a veces en cuestionamientos políticos a autoridades locales. Este escenario remata veinte años de incentivos públicos orientados a localizar vivienda en áreas centrales equipadas, y que ahora advierten -en sentido inverso- una saturación residencial sin una reproducción equivalente de servicios y equipamiento.

En este contexto, el presente artículo analiza los resultados de una encuesta de hogares levantada durante el año 2012 en cinco zonas de renovación urbana (ZRU) del AMGs, y un análisis económico de una serie histórica 2000-2012 de precios de venta de suelo logrados por residentes propietarios, y de vivienda nueva ofertada en cada una de las zonas. La selección de zonas se realizó de acuerdo con criterios de concentración de proyectos inmobiliarios de edificación en altura, y las actuales normativas urbanísticas derivadas de los planes reguladores respectivos. Estas zonas son: zona Centro (comuna de Santiago), zona Norte (comunas de Recoleta e Independencia), zona Poniente (comunas de Quinta Normal y Santiago), zona Sur (comuna de Macul) y zona Oriente (comuna de Nunnoa). La descripción del proceso de renovación urbana en cada una de ellas, y el análisis de los mecanismos institucionales y ajustes regulatorios aplicados, puede revisarse en publicaciones anteriores (López-Morales et al., 2012).

En cuanto a la encuesta, esta midió percepciones de residentes antiguos localizados en las áreas de influencia directa de los edificios de renovación urbana ubicados dentro de las zonas recién mencionadas, particularmente sobre efectos ambientales emanados de la construcción en altura, devaluación de propiedades y expectativas de relocalización de esos residentes. Por su parte, el análisis económico contó con la utilización de datos de precios de suelo vendido por propietarios originales y vivienda nueva ofertada, información que permitió visualizar la posibilidad real de relocalización de residentes originales (pre renovación urbana) dentro de la nueva oferta residencial de renovación urbana en sus barrios. Visto de la manera inversa, la relación entre estos dos factores hace posible establecer el grado de "exclusión" del mercado residencial, o potencial de desplazamiento de residentes originales por parte del mismo mercado en cada una de las zonas. Pensamos que este resultado es importante, porque se lo puede extrapolar a las comunas del centro y pericentro de Santiago, contexto caracterizado por altas tasas de propiedad $(70 \%)$ y, como se aprecia en los resultados analizados más adelante, con población que demuestra muy altas expectativas de conseguir relocalización en suelo central en caso de vender sus propiedades, actualmente habitadas, a los desarrolladores.

El concepto de "exclusión" por incapacidad económica remite a las consideraciones teóricas desarrolladas por Slater (2009) y Aalbers (2011) desde una perspectiva crítica de los mercados de recambio urbano (exclusionary displacement como procesos de denegación de acceso de segmentos sociales a ciertos espacios residenciales o urbanos), así como por los trabajos del Lincoln Institute referidos a recuperación estatal de plusvalías de renta de suelo urbano y su posible uso en reinversión pública en vivienda de interés social y bienes públicos localizados en suelo central (land value capture), con Smolka (2013) como uno de los referentes más completos y actualizados. 


\section{Metodología y definición de zonas de estudio}

Pensamos que la encuesta de hogares aplicada en esta investigación es uno de los primeros estudios latinoamericanos con base estadística representativa y orientación cuantitativa al análisis de prácticas y efectos asociados a recambio y exclusión social en espacio central, y una de las pocas encuestas internacionales que se focaliza en vecinos aledaños a (y no al interior de) edificios de renovación, esto es, vecinos antiguos que son afectados por la renovación urbana.

El instrumento fue diseñado para los residentes de propiedades no renovadas, en zonas o barrios ya "colonizados" por edificios de renovación urbana, y que, por ende, residen en predios con alguna expectativa de ser adquiridos en el futuro próximo con el fin de ser utilizados para construir edificación nueva en altura. Cada uno de estos barrios fue abordado por medio de un muestreo estratificado representativo. La encuesta incluyó residentes locales propietarios y arrendatarios, ya sea en modalidad de monoarriendo o multiarriendo (esta última generalmente usada por inmigrantes de bajos ingresos).

En términos específicos, la encuesta se dirigió a jefes de hogar o cónyuges residentes en propiedades sometidas a renovación de barrios que cumplían los filtros o requisitos del estudio. El instrumento plantea secciones de: i) identificación de integrantes; ii) cuantificación y cualificación de población residente; iii) respuestas de percepción-evaluación del proceso de renovación; iv) disposición a la venta de suelo; v) expectativas habitacionales de reemplazo, y vi) ingreso promedio mensual del hogar. Asimismo, la encuesta fue diseñada conforme al marco teórico del estudio, sustentado en una propuesta sometida a la discusión con expertos académicos y activistas en una primera ronda de validación del instrumento, que luego fue sometida a un proceso de pre test de terreno, que condujo a modificaciones y correcciones. Los nombres de los encuestados no fueron incluidos en el análisis con el fin de resguardar su anonimato.

CUADRo I | Zonas específicas, total y porcentaje de encuestas obtenidas por zonas

\begin{tabular}{|l|l|c|c|}
\hline \multicolumn{1}{|c|}{ COMUNA } & \multicolumn{1}{|c|}{ ZONA } & $\begin{array}{c}\text { NÚMERO DE } \\
\text { ENCUESTAS }\end{array}$ & PORCENTAJE \\
\hline Santiago Centro & Zona Centro: avenida Santa Isabel & 196 & $26 \%$ \\
\hline Recoleta-Independencia & Zona Norte: sector La Chimba & 121 & $16 \%$ \\
\hline Nuñoa & Zona Oriente: sector Irarrázaval Poniente & 161 & $22 \%$ \\
\hline Macul & Zona Sur: sector avenida Macul & 131 & $18 \%$ \\
\hline Quinta Normal & Zona Poniente: sector Estación Yungay & 137 & $18 \%$ \\
\hline TотAL & & 746 & $100 \%$ \\
\hline
\end{tabular}

FUENTE ELABORACIÓN PROPIA

Se levantó un total de 746 encuestas con un margen de error inferior a $+/-8,5 \%$ en cualquier estrato e inferior al $5 \%$ en el total de la muestra. Los hogares encuestados suman más de dos mil personas empadronadas en la hoja de población. Los 
casos por encuestar fueron fijados imputando encuestas de modo proporcional a la importancia relativa de las manzanas constituyentes del área de influencia o barrio de cada caso, a partir de datos censales poblacionales del ańo 2002 (Instituto Nacional de Estadísticas [INE], 2003). La aplicación de la encuesta se desarrolló entre los meses de abril y mayo de 2012 y tuvo buena respuesta, a excepción de sectores afectados por gran cantidad de viviendas deshabitadas, específicamente en la zona Centro, que fueron imposibles de previsualizar con el instrumento censal de 2002. El dato de comunas, zonas específicas analizadas, número de encuestas por zona y porcentaje respecto al total se muestran en el Cuadro 1.

FIGURA I | Mapa de zonas de estudio y comunas respectivas

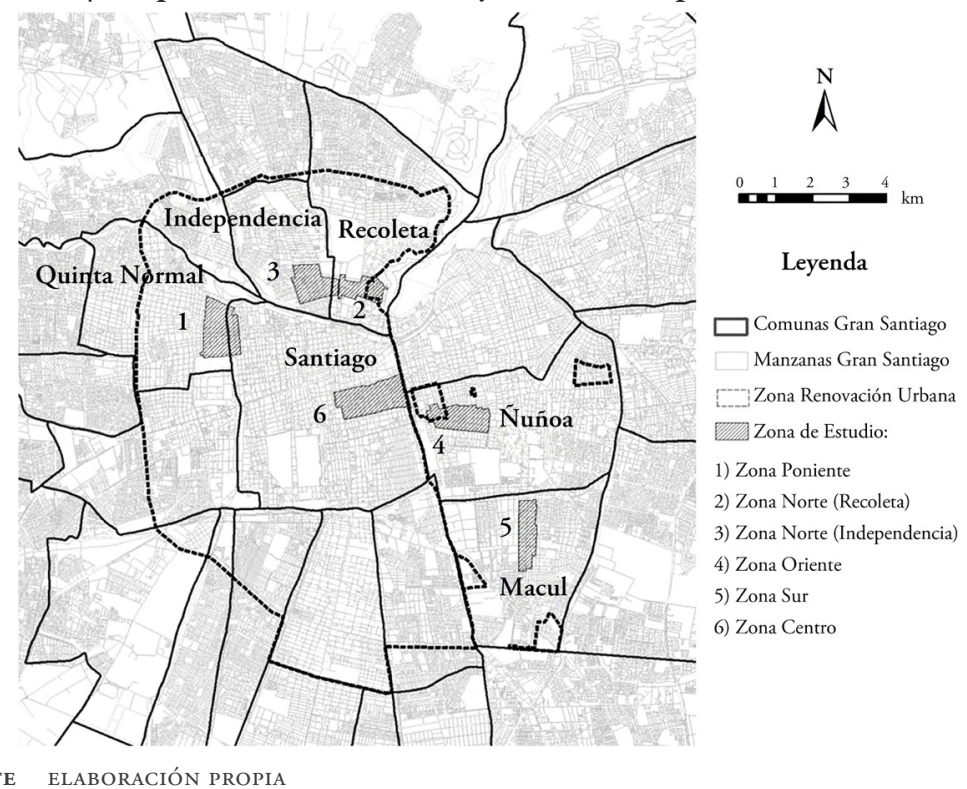

FUENTE ELABORACIÓN PROPIA

La encuesta arrojó datos valiosos de percepción de residentes originales respecto a la valorización de sus propiedades, entorno urbano inmediato y proyecciones futuras residenciales. Ese dato fue contrastado con un análisis de las posibilidades reales de obtención de renta de suelo por venta de sus propiedades a desarrolladores inmobiliarios, basado en series históricas de precio pagado por paños de suelo (indicados en $\left.\mathrm{UF} / \mathrm{m}^{2}\right)^{2}$ por parte de inmobiliarias, para operaciones inmobiliarias desarrolladas entre 2000 y 2012. Consideramos como "renta del suelo" aquel dato correspondiente a los precios de venta de las propiedades que venden los residentes originales de las zonas de renovación, dado que es posible entenderlo como una porción de la ganancia del productor inmobiliario que es capturada por el propietario en virtud de la localización que posee su predio, ya que en todos los casos considerados se

La UF es una unidad de cuenta utilizada en Chile, autoajustable de acuerdo con la inflación: 1 uF equivale a 24.000 pesos chilenos, o 42 dólares, a agosto 2014 . 
trata de "renovación" con demolición de la vivienda preexistente, es decir, de todo el capital fijo que pudiese alterar la identificación conceptual entre precio y renta de suelo urbano (referencias teóricas en Clark, 1988, y Jaramillo, 2009, entre otros).

La proyección de renta de suelo obtenible se calcula de acuerdo al plano de división predial y el precio de suelo unitario por metro cuadrado promedio que han obtenido los propietarios anteriores que han vendido sus predios en la misma zona. Se realizó luego una estimación de una "tasa de relocalización" (T), que es el cociente entre el precio de suelo total obtenible de acuerdo con las series observadas de precio de suelo pagado, y el precio de departamentos nuevos ofertados dentro de la zona estudiada, asumido como necesario para relocalizarse dentro de la misma zona. Esto implica suponer que el propietario-residente original destina la totalidad de su renta de suelo obtenida a la compra de su nueva vivienda de reemplazo, sin necesidad de solicitar créditos o cualquier tipo de flujo económico externo a la venta de su propiedad. "T" equivale a la proporción del departamento demandado (considerando la oferta dentro de cada zona estudiada) por un hogar encuestado, que se solventa con la renta posible de obtener por la venta de la propiedad a las empresas inmobiliarias que operan en la misma zona de renovación. "T" se resume entonces de la siguiente manera:

$$
\mathrm{T}=[\mathrm{R} * \mathrm{~S}] / \mathrm{P}
$$

donde " $R$ " es la renta relativa, " $S$ " la superficie predial y " $P$ " el precio del departamento demandado por el hogar encuestado ${ }^{3}$.

\section{Encuesta a vecinos de barrios en renovación urbana: perfiles, percepciones y expectativas de venta de propiedad y movilidad residencial}

Caracterización etaria, educacional y de ingreso de la población encuestada

Los hogares encuestados suman un total de 2.430 personas residentes de los lotes controlados. Según los datos recabados, la distribución por sexo y edades de la población residente antigua de los barrios sometidos a renovación es diferente al promedio de la población urbana chilena. Como promedio, los vecinos aledaños a proyectos de renovación urbana reportan una sobrerrepresentación de edades intermedias y mayores de edad, segmento de 20 a 34 ańos, además de mostrar una significativa presencia de adultos mayores, particularmente de sexo femenino. De las personas que contestaron la encuesta (propietarios y arrendatarios), en un 53\% se trata de mujeres. Dos tercios de los entrevistados (67\%) se identificaron como

3 El factor "R" tiene un valor paramétrico (promedio por zona) para los residentes originales actuales encuestados que vendan sus propiedades y quieran relocalizarse dentro de la misma zona; "S" es la superficie predial que posee cada propietario de hogar encuestado (según Planos de División Predial dispuestos por los respectivos municipios); y "P" es el precio medio de los departamentos ofertados en las zonas de renovación al año 2012, según el sitio web Portal Inmobiliario. Se desagregaron los datos por tipología demandada (1, 2 y 3 dormitorios), por lo que " $\mathrm{P}$ ” no es igual para todos los propietarios-residentes de una misma zona, ya que la tipología demandada está en función de la cantidad de integrantes del hogar encuestado. 
jefe/a de hogar de la vivienda encuestada como promedio, mientras que el restante tercio se divide entre esposo/a o pareja del jefe/a (14\%) y una diversidad de otras formas de parentesco con el jefe/a; por ejemplo, hijos.

GRÁfICo I | Pirámide de edades de población de residentes y nivel educacional de jefes/as de hogar en lotes encuestados por zonas

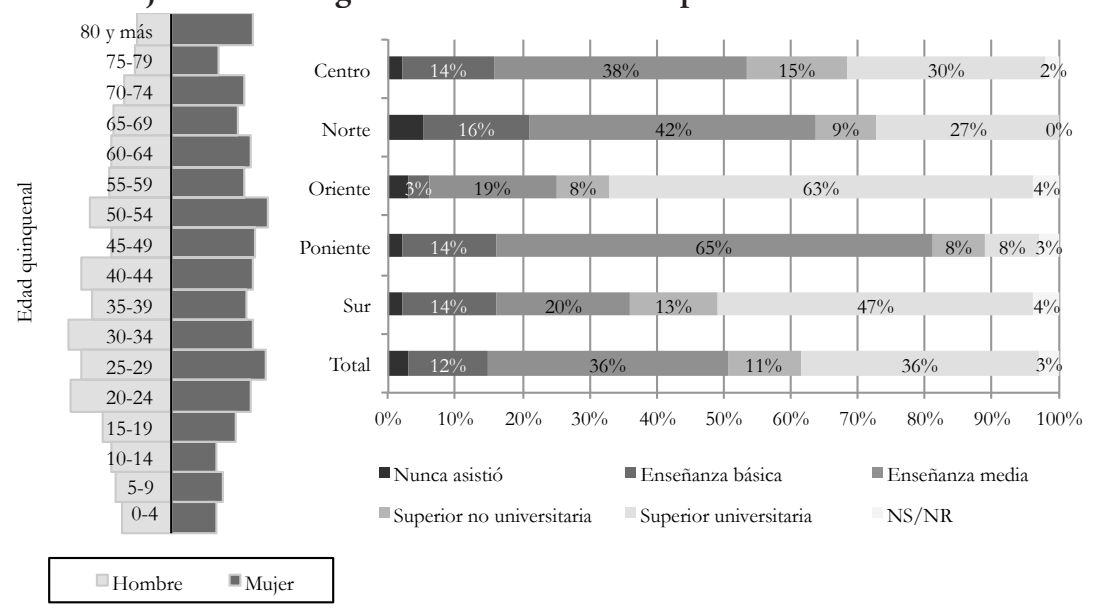

FUENTE ELABORACIÓN PROPIA

El Gráfico 1 muestra que los jefes de hogar de las viviendas vecinas a la renovación destacan por su diversidad de niveles de instrucción (variable clásicamente vinculada a diferencias del nivel de expectativas y exigencias por calidad de vida). En términos generales, más de un tercio (36\%) está constituido por profesionales universitarios, otro tercio solo alcanzó a cursar enseńanza media y el resto se divide entre quienes cursaron estudios de enseñanza básica o nunca asistieron (20\%), y un $11 \%$ que cursó educación técnica superior. No obstante, se trata de un perfil que varía mucho por zonas o barrios. Las zonas Oriente (Nuñoa) y Sur (Macul) muestran mayor presencia de profesionales universitarios (65\% y $42 \%$, respectivamente), mientras que en las zonas Norte (comunas de Recoleta e Independencia) y Poniente (Quinta Normal) existe bastante menor escolaridad y predominan jefes de hogar que solo cursaron hasta enseńanza media. Ante la pregunta sobre ingresos mensuales por hogar, aparece un número considerable de respuestas con valores inferiores a $\$ 600.000$ en los casos de zonas Poniente (63\%), Centro (54\%) y Norte (49\%), mientras que porcentajes más bajos dentro de ese rango se registran en las zonas Sur $(28 \%)$ y Oriente $(21 \%)$, reflejando con claridad las diferencias socioeconómicas de la población original residente en estas zonas. Las dos últimas zonas corresponden a comunas aledañas al "barrio alto" del AMGs.

\section{Efectos de la renovación urbana sobre barrios y calidad de vida}

Todos los hogares encuestados se encontraban en las zonas de renovación urbana establecidas; de ellos, más del 70\% comparte calle o manzana con al menos un 
proyecto inmobiliario, habiendo un $45 \%$ de estos directamente colindante, mientras $21 \%$ convive con dos o más proyectos de renovación urbana al interior de la misma manzana. Esto indica que los resultados reflejan percepciones de vivencias de vecinos ubicados en el primer (dentro de la misma manzana) o segundo anillo (manzanas colindantes) del área de influencia del impacto inmobiliario. En cuanto a la situación habitacional, se observa que en su mayor parte los hogares encuestados son propietarios del inmueble que ocupan (56\%) y una proporción bastante menor $(27 \%)$ corresponde a arrendatarios. En promedio, las viviendas en las que se aplicó la encuesta se caracterizan por una data antigua de construcción (en un 68\% de los casos las viviendas encuestadas fueron construidas con anterioridad a 1960). En contraste, la zona Sur es la única que registra mayormente viviendas construidas después de 1960, por estar dentro de la comuna de Macul, periférica en el área urbanizada de Santiago y aún semirrural a esa fecha.

En lo que respecta a la percepción de los habitantes sobre sus entornos en un estado previo a la renovación urbana, entre los aspectos más valorados destacan fuertemente las ventajas de localización, condición que no solo se refleja en una mayor accesibilidad relativa a servicios y transporte, sino también en la idea más abstracta de vivir en un lugar central bien ubicado. Sin embargo, entre las consecuencias percibidas por los vecinos/as ante la llegada de edificios en altura, la gran mayoría de los encuestados manifiesta algún efecto directo negativo asociado a la presencia de estas construcciones, lo que refleja igual satisfacción por su localización y calidad de atributos, pero descontento con el impacto o efecto directo de los edificios en cuestiones microambientales del área de influencia directa.

$\mathrm{Al}$ respecto, para las cinco zonas en promedio, la proyección de sombras a algunas horas del día es visualizada como la externalidad negativa menos significativa, con una consecuencia relevante para menos de la mitad de los vecinos/as (45\%). Asimismo, un 50\% manifiesta que los edificios han generado congestión en las calles y otro 53\% reconoce el efecto negativo que estas construcciones han provocado en términos de generar un obstáculo visual en el entorno (interrupción de las vistas). La mayoría de los residentes refuta posibles efectos positivos derivados de la construcción de proyectos de renovación urbana. Un 69\% y un 70\% de los vecinos/as opina que la llegada de edificaciones no ha significado una mejoría de las condiciones de seguridad ni de iluminación del entorno, respectivamente.

Estas externalidades son percibidas con diferente intensidad por los residentes, dependiendo de las distintas zonas consultadas. Los impactos negativos en materia de vistas, congestión y sombras son ampliamente reconocidos por los habitantes de la zona Centro, con 66\%, 61\% y 60\%, respectivamente. Esto era un resultado esperable en la medida en que se sabe que la densidad y altura de construcción en la zona Centro es mayor que en el pericentro, producto de su normativa urbana mucho más permisiva hasta el año 2012, pero de igual manera los valores fueron sorpresivamente altos. En el caso de las zonas Oriente y Sur, los efectos negativos más importantes se concentran en vistas y congestión, siendo menos importante el impacto de las sombras. En relación con la zona Norte, la principal consecuencia negativa se percibe en el ámbito de la congestión vehicular. Los habitantes de la zona Poniente, en tanto, revelan mejores percepciones del proceso que los demás 
barrios, reduciéndose mucho los efectos de sombra, interrupción de la vista y congestión, producto del mayor distanciamiento entre proyectos inmobiliario de alto impacto por altura y volumen construido.

CUADRO 2 | Efectos directos percibidos por la presencia de edificios en altura por zonas estudiadas

\begin{tabular}{|l|c|c|c|c|c|c|}
\hline $\begin{array}{l}\text { EFECTOS DIRECTOS PERCIBIDOS } \\
\text { POR LA PRESENCIA DE EDIFICIOS } \\
\text { EN ALTURA }\end{array}$ & CENTRO & NORTE & ORIENTE & PONIENTE & SUR & PROMEDIO \\
\hline $\begin{array}{l}\text { Recibe sombra por lo menos a } \\
\text { algunas horas }\end{array}$ & $60 \%$ & $41 \%$ & $48 \%$ & $22 \%$ & $48 \%$ & $45 \%$ \\
\hline Interrumpe vista & $66 \%$ & $43 \%$ & $65 \%$ & $23 \%$ & $56 \%$ & $53 \%$ \\
\hline No hay mejora de iluminación & $76 \%$ & $68 \%$ & $64 \%$ & $68 \%$ & $82 \%$ & $70 \%$ \\
\hline No hay mejora de la seguridad & $70 \%$ & $66 \%$ & $71 \%$ & $72 \%$ & $66 \%$ & $69 \%$ \\
\hline Genera congestión en su calle & $61 \%$ & $55 \%$ & $52 \%$ & $23 \%$ & $56 \%$ & $50 \%$ \\
\hline
\end{tabular}

FUENTE ELABORACIÓN PROPIA

Por otra parte, en lo que se refiere a servicios privados, cabe destacar que casi un $60 \%$ de los vecinos percibe la atracción de comercios y restaurantes como la ganancia de servicios privados más relevante asociada al proceso de renovación urbana. Secundariamente, la llegada de gimnasios (47\%) y facilidades de transporte (35\%) aparecen como también relevantes. No obstante, estos servicios privados se perciben mayormente en la zona Oriente y en menor medida en las otras zonas, en especial la zona Poniente, que registra una percepción especialmente baja de ellos.

CUADro 3 | Percepción de la llegada de servicios privados por zonas de estudio

\begin{tabular}{|l|c|c|c|c|c|c|}
\hline $\begin{array}{c}\text { TIPO DE EQUIPAMIENTO O } \\
\text { SERVICIO }\end{array}$ & CENTRO & NORTE & ORIENTE & PONIENTE & SUR & PROMEDIO \\
\hline Clínicas & $12 \%$ & $22 \%$ & $16 \%$ & $7 \%$ & $36 \%$ & $18 \%$ \\
\hline Gimnasios & $49 \%$ & $55 \%$ & $61 \%$ & $30 \%$ & $36 \%$ & $47 \%$ \\
\hline Transporte & $32 \%$ & $32 \%$ & $41 \%$ & $38 \%$ & $33 \%$ & $35 \%$ \\
\hline Restaurantes & $57 \%$ & $51 \%$ & $76 \%$ & $36 \%$ & $62 \%$ & $57 \%$ \\
\hline Comercio & $62 \%$ & $58 \%$ & $64 \%$ & $42 \%$ & $67 \%$ & $59 \%$ \\
\hline
\end{tabular}

FUENTE ELABORACIÓN PROPIA

Paralelamente, se consultó si hubo mejoras por inversiones en infraestructura urbana colectiva, colaterales o simultáneas a la producción de edificios de renovación urbana. La percepción de los residentes muestra un menor nivel de mejoras. Solo se destaca la iluminación de calles o pasajes, aspecto relevado por un $37 \%$ de los encuestados/as. Un 31\%, en tanto, seńala haber apreciado impactos a nivel de pavimentación de calles y veredas, y otro $29 \%$ registra la presencia de señalética nueva. Elementos y accesorios para la circulación vehicular, tales como semáforos o lomos de toro, en tanto, recogen la menor frecuencia de menciones (19\% y 21\%). 
CUADro 4 | Tipo de obra o inversión urbana por zonas de estudio

\begin{tabular}{|l|c|c|c|c|c|c|}
\hline \multicolumn{1}{|c|}{$\begin{array}{c}\text { TIPO DE OBRA O } \\
\text { INVERSIÓN URBANA }\end{array}$} & CENTRO & NORTE & ORIENTE & PONIENTE & SUR & PROMEDIO \\
\hline Iluminación de calles o pasajes & $34 \%$ & $44 \%$ & $45 \%$ & $29 \%$ & $35 \%$ & $37 \%$ \\
\hline Pavimentación de calles y veredas & $34 \%$ & $27 \%$ & $29 \%$ & $27 \%$ & $38 \%$ & $31 \%$ \\
\hline Seńalética & $27 \%$ & $26 \%$ & $27 \%$ & $33 \%$ & $31 \%$ & $29 \%$ \\
\hline Semáforos & $19 \%$ & $21 \%$ & $14 \%$ & $21 \%$ & $22 \%$ & $19 \%$ \\
\hline Lomos de toro & $13 \%$ & $19 \%$ & $24 \%$ & $25 \%$ & $27 \%$ & $21 \%$ \\
\hline
\end{tabular}

FUENTE ELABORACIÓN PROPIA

A efectos de disponer de un indicador resumen de lo anterior, se construyó un índice

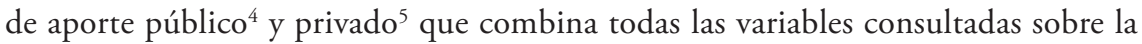
llegada de posibles tipos de equipamiento colectivo o bienes públicos, con el fin de medir el delta del impacto urbano entre la situación actual y anterior percibidas. A diferencia del impacto urbano de tipo privado, la existencia de aporte público destaca por tener una muy baja percepción entre los vecinos de estas zonas. Al desagregar estos datos por los barrios estudiados, pese a que todos siguen la tendencia señalada, se advierte una variación entre las zonas encuestadas. En efecto, casos como los de los vecinos de Santa Isabel (zona Centro) o avenida Irarrázaval Poniente (zona Oriente) ejemplifican de manera clara el bajo aporte al equipamiento público, mientras que en las zonas Norte y Sur los residentes plantean percibir mejoras.

Al comparar los índices de percepción de mejoras en servicios privados versus mejoras en equipamiento colectivo se registran claras diferencias. En efecto, para el promedio de las cinco zonas, el porcentaje de personas que percibe que no hay ninguna mejora en aporte público es de 40,8\%, mientras que la percepción de que no hay ningún aporte privado es de un $15,7 \%$. Esto se ve matizado entre los que contestan que existe solo una mejora de servicios privado (17\%), versus solo una mejora de impacto público (21\%). En los niveles de mayor aporte urbano, el índice de percepción de mejora de servicios privados es muy superior al de percepción de mejora de equipamiento público (14\% y $7 \%$, respectivamente). En suma, un dato clave de considerar es que la renovación urbana residencial acarrea un mayor

4 La construcción del índice de impacto urbano púbico positivo se realizó a partir de la siguiente pregunta: "Durante y después de la construcción de los edificios en altura, ¿̨cuáles obras de mejoramiento del barrio se han realizado?".

a. Iluminación de calles o pasajes Sí $(+1) / \mathrm{NO}(+0)$

b. Pavimentación de calles y veredas Sí $(+1) / \mathrm{NO}(+0)$

c. Señalética Sí $(+1) / \mathrm{NO}(+0)$

d. Semáforos Sí $(+1) / \mathrm{NO}(+0)$

e. Lomos de toro Sí $(+1) / \mathrm{NO}(+0)$

5 La construcción del índice de impacto urbano privado positivo se realizó a partir de la siguiente pregunta: “¿Cuáles de estos servicios han llegado al barrio con la renovación urbana?”.

a. Clínicas SÍ $(+1) / \mathrm{NO}(+0)$

b. Gimnasios SÍ $(+1) / \mathrm{NO}(+0)$

c. Transporte SÍ $(+1) / \mathrm{NO}(+0)$

d. Restaurantes SÍ $(+1) / \mathrm{NO}(+0)$

e. Comercios Sí $(+1) / \mathrm{NO}(+0)$ 
impacto urbano de tipo privado, por sobre los aportes del sector público; es decir, proliferan bienes pagados al momento de utilizarlos, y esta situación es percibida con diferencias por los vecinos de los barrios estudiados.

GRÁfICO 2 Comparación de percepción de impacto urbano privado y público de tipo positivo

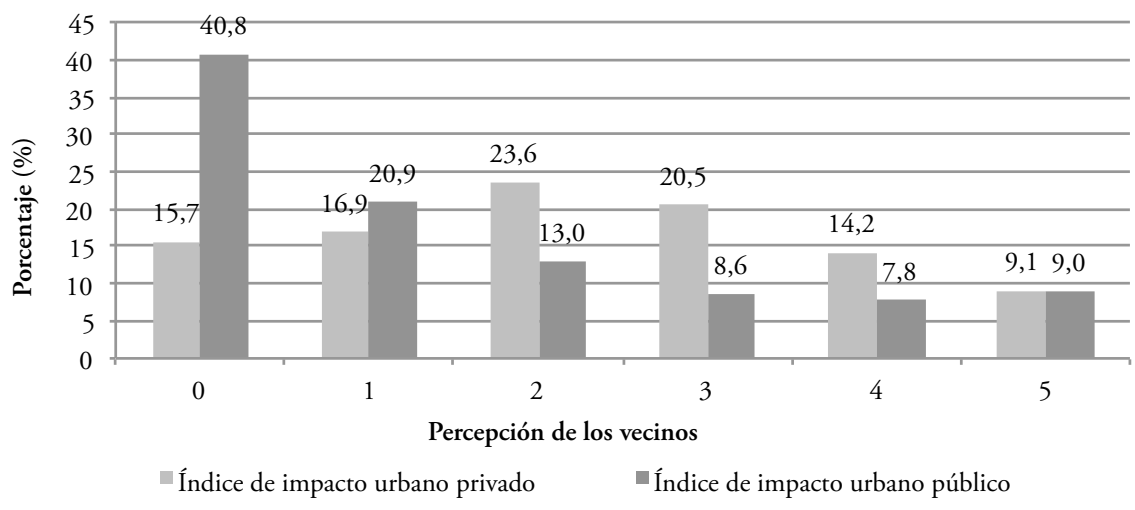

FUENTE ELABORACIÓN PROPIA

El otro dato clave es que, desagregadas las cinco zonas y para el total de percepciones frente a impactos en mejoramientos de aporte público y privado, las diferencias de percepción dependiendo de la zona son bastante notables. En la zona Centro se visualiza el mayor porcentaje de respuestas negativas tanto frente a aporte público (73\%) como privado (49\%). Sin embargo, por el contrario, las zonas donde se concentra el mayor número de respuestas positivas respecto a aportes públicos es la Sur (65\%); y frente a aportes privados, la Oriente (40\%). Estas diferencias permiten inducir que, para un mayor o menor aporte público y privado, las diferencias de precio promedio de los departamentos nuevos ofrecidos (que en gran medida refleja el target socioeconómico al que aspiran las inmobiliarias) podría ser una variable explicativa de estas distintas percepciones, ya que el precio promedio de los departamentos nuevos vendidos en la comuna de Santiago (zona Centro) se sitúa entre los más bajos de las cinco zonas (véase Cuadro 5), mientras que la zona Oriente es la que muestra los precios de departamentos más altos. Es en este último lugar donde las inmobiliarias y empresas de servicios pueden invertir mayores recursos, con el fin de generar ambientes acordes al perfil de sus nuevos habitantes y asegurar una alta demanda.

En lo que refiere al impacto de la renovación urbana en la calidad de vida de los habitantes, cabe destacar que esta sigue siendo buena, pero ha disminuido de nivel. En efecto, el índice de percepción de satisfacción del barrio propuesto en la encuesta que consultó la nota de evaluación de los propios vecinos sobre el escenario 
anterior y posterior a la llegada de proyectos de renovación urbana, arrojó una nota promedio de 6,0 a la situación previa, mientras que la nota que adjudican para calificar la situación actual apenas alcanza un valor promedio de 4,8, lo que es una variación significativa.

Coincidiendo con el primer índice analizado -el de los efectos directos percibidos por la presencia de edificios-, la zona Centro recibió la nota actual más baja. Oriente recibió una mejor nota, puesto que la llegada de nuevos servicios ha compensado de manera más clara efectos posiblemente negativos. Por su parte, las zonas Norte y Sur muestran tendencias similares. Por un lado, la zona Norte, a pesar de no mostrar efectos visibles asociados a la construcción en altura tan importantes como la zona Centro, tiene la peor evaluación anterior y luego una mala evaluación actual, probablemente por la baja inversión pública percibida. Ello ocurre de manera similar en la zona Sur, que presenta una de las bajas más notorias de calificación, probablemente por una combinación de externalidades negativas asociadas a la construcción en altura, aunque no por falta de inversión pública y privada, que es percibida como de las más altas. Finalmente la zona Poniente declara la nota actual más alta, cercana a la nota previa, en un contexto de proyectos concentrados en el sector industrial -considerado molesto-, donde casi no existen vecinos anteriores, y dispersos en el resto del área en cuestión, lo que genera una baja percepción de cambios en general.

GRÁfICO 3 | Evaluación de la calidad de vida en el barrio antes y después de la renovación urbana

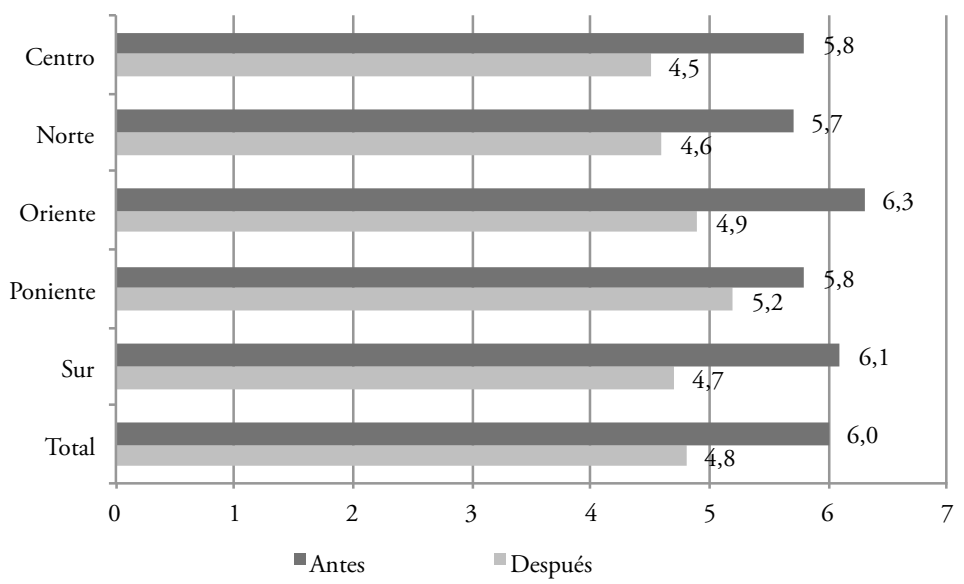

FUENTE ELABORACIÓN PROPIA

Ahora, al analizar las expectativas de los habitantes respecto al supuesto de que seguirán llegando edificios de renovación urbana, dos tercios de los encuestados/as se muestran de acuerdo con la afirmación de que "cambiarán de modo notable los habitantes y familias del sector". Esta percepción de que pueden existir cambios de gran trascendencia en el barrio resulta más intensa entre los vecinos/as de las zonas Norte y Oriente, llegando a más de un $70 \%$. 
GRÁFICO 4 | Proyecciones sobre el barrio ante la renovación urbana

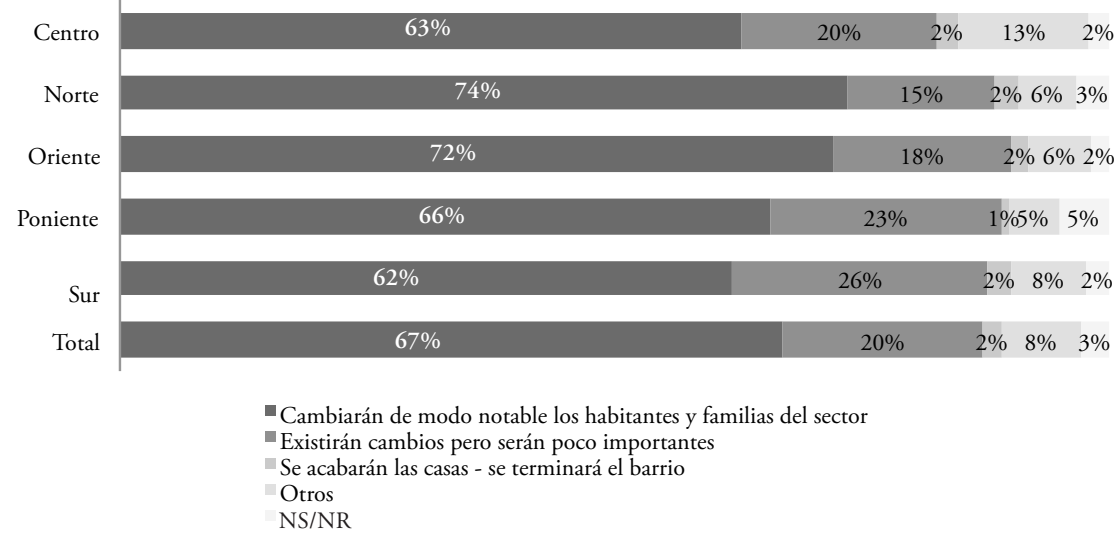

FUENTE ELABORACIÓN PROPIA

Incidencia percibida en la renta potencialmente obtenible por parte del encuestado En cuanto a las percepciones de los encuestados sobre los efectos de la renovación urbana en lo que sería la valorización de sus viviendas (Gráfico 5), un 77\% declaró que estas habrían aumentado su valor en alguna medida; y de ellos, un 59\% declara que el valor de las viviendas ha aumentado mucho (2 millones de pesos o más), mientras un $18 \%$ sostiene que se han producido incrementos moderados (entre 500.000 y 1 millón y medio de pesos). Complementariamente, un $11 \%$ del total indica que las propiedades valen lo mismo que antes y solo un $6 \%$ manifiesta que el valor de las viviendas ha decaído en una magnitud moderada o significativa.

Dentro de este cuadro general, se detectan diferencias entre los encuestados/as de las distintas zonas. En las zonas Oriente y Sur (comunas de Nunñoa y Macul), el porcentaje de encuestados que manifiesta haber observado aumentos en el valor de sus viviendas alcanza al $85 \%$ y $83 \%$, respectivamente, con más de un $65 \%$ que identifica incrementos de más de \$2 millones. A estos casos le sigue la zona Centro, donde la percepción en torno al aumento de precios de las viviendas llega al 76\%. Las zonas Norte y Poniente (Recoleta, Independencia, Quinta Normal) perciben menores alzas de precios, con menos de la mitad de los encuestados/as que declara aumentos significativos en el valor de sus viviendas.

Sobre las causales de entorno de estas respuestas, en el caso de quienes tienen la impresión de que el valor de las viviendas ha aumentado, un tercio destaca como motivos principales (Gráfico 6) las mejoras a nivel de infraestructura pública (38\%), un $22 \%$ la disponibilidad de comercio y servicios $(22 \%)$ y un $21 \%$ la presencia de edificios en altura. Por contrapartida, para los que sostienen que el valor de las viviendas se ha mantenido o decaído, el principal factor que lo explicaría es la presencia de edificación en altura en el barrio (28\%), lo que revela la complejidad que revisten los efectos del proceso de renovación urbana en las percepciones de los residentes. 
Hay que seńalar, sin embargo, que la creencia generalizada sobre las propiedades en zonas en proceso de construcción en altura es que su valor va al alza "siempre"; por tanto, una respuestas de incremento moderado equivale en rigor a una respuesta neutra, y una respuesta que indica que la propiedad vale lo mismo implica una disminución relativa respecto a otros barrios y el resto de Santiago, cuyos valores promedio de propiedades se han triplicado entre 1990 y 2010.

GRáfico 5 | Percepción de los vecinos sobre el valor de sus viviendas después de la llegada de los edificios

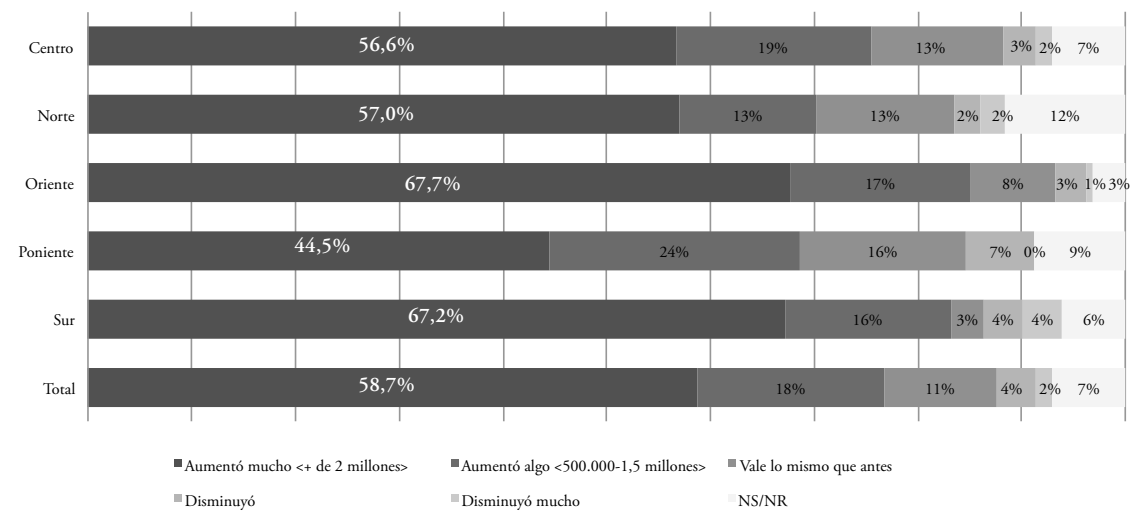

FUENTE ELABORACIÓN PROPIA

GRÁfICo 6 | Principales motivos sobre el aumento, disminución o mantención del valor de la vivienda

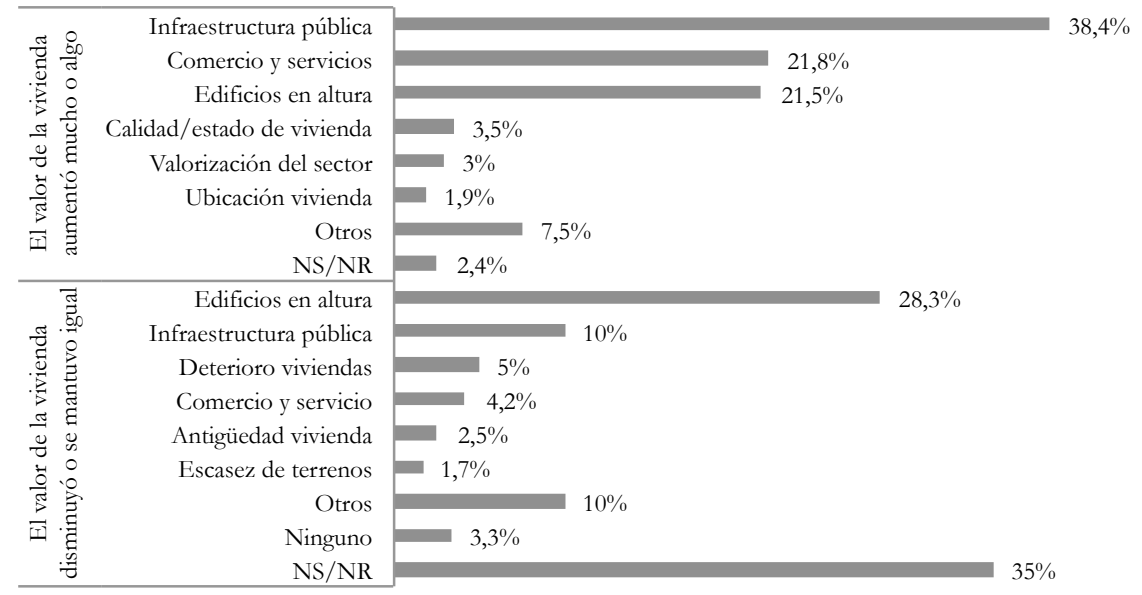

FUENTE ELABORACIÓN PROPIA 
Análisis de escenarios de renta realmente obtenible por parte del encuestado

Ahora bien, las expectativas de los residentes pueden ser contrastadas con un análisis histórico de los precios realmente obtenidos en la compra-venta de propiedades para renovación urbana en estas zonas. Para ello, se rastreó en el Conservador de Bienes Raíces de Santiago las transacciones de propiedades vendidas por dueños de viviendas en los sectores en estudio a empresas inmobiliarias que hayan edificado proyectos de renovación urbana en el período 2000-2010. Se consideraron los predios vendidos particularmente por personas naturales, con el fin de filtrar agentes intermediarios de carácter rentista o personas jurídicas con giro industrial/comercial. A saber, este análisis se ha realizado para cuatro de las cinco zonas, excluyendo la zona Poniente, y considerando solo la parte de la zona Norte correspondiente a la comuna de Recoleta. Esta reducción se debe a que en las comunas de Quinta Normal e Independencia el número de casos de transacciones de terrenos es sustancialmente menor, lo que hace a ambas zonas menos relevantes estadísticamente. Tras este análisis se obtuvieron los resultados expresados en el Cuadro 5 en términos de renta relativa $\left(\mathrm{UF} / \mathrm{m}^{2}\right)$ y renta total estimada (UF) en función de los tamaños promedios de lotes encontrados para cada zona, según los planos catastrales municipales. El cuadro también muestra por cada zona el tamaño promedio de los departamentos nuevos ofrecidos, su precio promedio y relación $\mathrm{precio} / \mathrm{m}^{2}$.

CUADRo 5 | Rentas de suelo obtenidas por propietarios de suelo tras venta a inmobiliarias en período 2000-2010 y precios y tamańos promedio de vivienda nueva ofrecida por zona

\begin{tabular}{|l|c|c|c|c|}
\cline { 2 - 5 } \multicolumn{1}{c|}{} & CENTRO & ORIENTE & SUR & $\begin{array}{c}\text { NORTE } \\
\text { (RECOLETA) }\end{array}$ \\
\hline Renta relativa media $\left(\mathrm{UF} / \mathrm{m}^{2}\right)$ & 12,63 & 15,97 & 11,68 & 11,67 \\
\hline Tamaño promedio de superficie de lotes $\left(\mathrm{m}^{2}\right)$ & 201,8 & 212,87 & 333,66 & 297,64 \\
\hline Renta total media (UF) & $2.287,74$ & $3.399,25$ & $3.896,21$ & $3.473,51$ \\
\hline Precio promedio departamento nuevo & $1.442 \mathrm{UF}$ & $2.844 \mathrm{UF}$ & $1.985 \mathrm{UF}$ & $1.630 \mathrm{UF}$ \\
\hline Tamańo promedio departamento nuevo & $54,7 \mathrm{~m}^{2}$ & $72,3 \mathrm{~m}^{2}$ & $52,9 \mathrm{~m}^{2}$ & $57,9 \mathrm{~m}^{2}$ \\
\hline $\mathrm{UF} / \mathrm{m}^{2}$ departamento nuevo & 26,4 & 39,3 & 37,5 & 28,2 \\
\hline
\end{tabular}

FUENTE ELABORACIÓN PROPIA

Dados estos valores, fue posible estimar la tasa de relocalización "T" para cada propietario-residente en cada zona, la cual equivale a la proporción del precio del departamento necesario para alojar a todos los integrantes de su hogar (considerando solamente la oferta de departamentos dentro de su zona, según se aprecia en el Cuadro 5) y que se solventaría con la renta posible de obtener por la venta de su propiedad.

Como primer resultado, se obtiene que el $57 \%$ de los propietarios-residentes encuestados obtiene tasas igual o mayor que 1, alcanzando a costear el departamento requerido en la misma zona de renovación con la renta obtenida de su propiedad. Del $43 \%$ de los casos que obtienen tasas menores a 1 , un $7 \%$ corresponde a propietarios que alcanzan a solventar menos de la mitad del precio del departamento que requieren, y un $27 \%$ solventa hasta el $80 \%$ del mismo precio. Estos datos ya 
permiten inferir sobre posibles escenarios de relocalización de los propietarios-residentes en departamentos de precio medio en el conjunto del pericentro estudiado, siendo necesario establecer una diferenciación por zona.

Se observan tasas de relocalización media considerablemente menores en la zona Centro, donde un 17,5\% de los propietarios-residentes encuestados tiene tasas inferiores a 0,5 . Esto indica que la renta posible de obtener, según los valores medios registrados para la zona y la superficie predial de cada propietario, alcanza para costear menos de la mitad del precio del departamento que requiere el propietario de acuerdo con la cantidad de habitantes de su hogar. Y solo un $49 \%$ de la muestra en la misma zona alcanzaría a solventar el precio del departamento requerido con la renta obtenida de su propiedad actual.

En contraposición a la zona Centro, la zona Sur (comuna de Macul) aparece como la zona con mayor " $T$ " de entre todos los casos estudiados. No presenta tasas inferiores a 0,50 y solo un $7 \%$ se sitúa entre 0,5 y 0,8 . De hecho, un $72 \%$ de la muestra podría relocalizarse en esta misma zona, lo cual ya es una cifra considerablemente superior a la presentada en la zona Centro. Por su parte, la zona Oriente sostiene un $6 \%$ de la muestra con tasas bajo los 0,5 y un total de $58 \%$ de hogares residentes potencialmente relocalizables en la misma zona. En la zona Norte (Recoleta), si bien corresponde a una muestra mucho más pequeña, encontramos un $60 \%$ de los encuestados potencialmente relocalizable en la misma zona.

El factor explicativo de lo anterior es, fundamentalmente, la diferencia sustantiva en la superficie de las propiedades entre las zonas. Si bien en términos relativos el precio unitario del suelo es similar, la superficie de las propiedades produce diferencias en la renta obtenida, las cuales determinan económicamente la relocalización de los residentes en las mismas zonas de renovación. Esta es la principal diferencia entre las zonas Sur y Centro, que difieren ostensiblemente en el indicador "T", aun cuando los precios de los departamentos nuevos ofrecidos sean levemente superiores en la primera.

Lo anterior adquiere mayor relevancia si se considera que, al analizar las rentas de suelo registradas en el Conservador de Bienes Raíces de Santiago, visualizamos que ellas no sostenían relaciones indirectamente proporcionales con la superficie del predio, sino que mantenían valores constantes donde la superficie no es factor explicativo o determinante en el precio unitario/relativo de la propiedad. Esto quiere decir que es poco verosímil la consideración de que los predios más pequeños se puedan vender a mayor precio unitario de suelo, lo que refuerza la idea de que en la zona Centro, sector Santa Isabel, exista una mayor probabilidad de desplazamiento de los residentes.

Un factor que consideramos importante es que si bien solo un $10 \%$ de los hogares señala que el inmueble que habita ha sido formalmente ofertado para su venta (a través de carteles o avisos), la mayoría ha tenido contacto con agentes inmobiliarios que han manifestado interés por adquirir la vivienda: un $34 \%$ indica haber recibido visitas de corredores de propiedades y otro $30 \%$ señala haber recibido volantes o llamadas telefónicas con la misma intención, durante el último año. Un 35\% declara conocer a otras personas en su misma manzana que ya han vendido su propiedad o están en conversaciones para hacerlo, lo que en conjunto configura 
un escenario de cierta presión por vender, e incluso de condiciones desventajosas para hacerlo cuando la empresa inmobiliaria ya ha adquirido una parcela de suelo al interior de la manzana, lo que detectamos que en jerga informal inmobiliaria se denomina como "pinchar la manzana".

GRÁfICo 7 | Tasas de relocalización residencial por zona de estudio

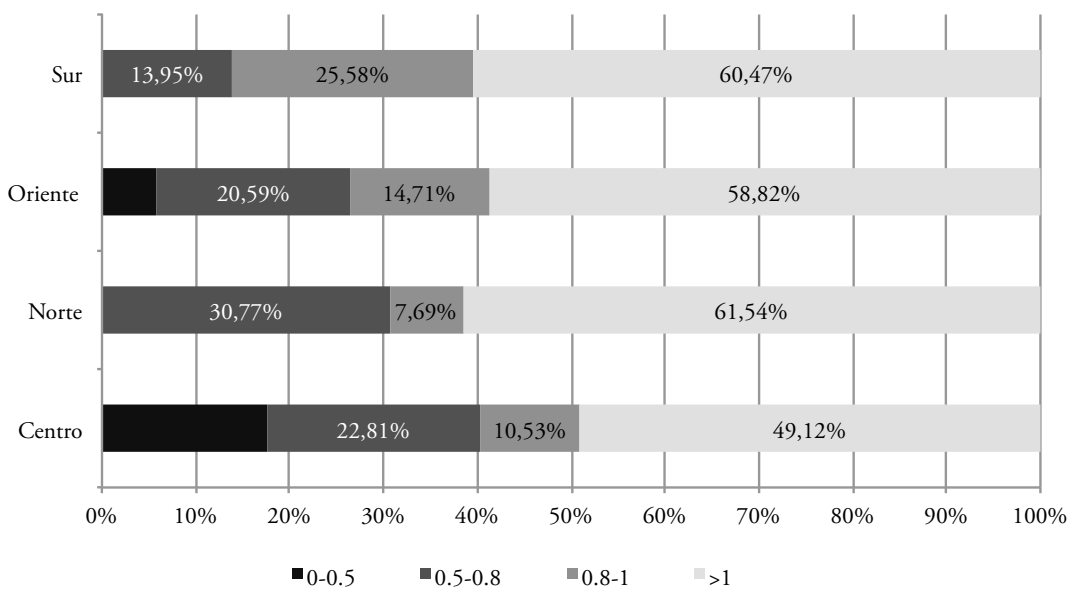

FUENTE ELABORACIÓN PROPIA

Preferencia habitacional de los residentes encuestados en las zonas de estudio

En la encuesta se pudo consultar directamente por un horizonte de futuro de cinco años, donde se obtuvo que más de la mitad de los residentes de las zonas en estudio expresa su intención de seguir residiendo en la misma vivienda que actualmente ocupa, mientras alrededor de un $40 \%$ declara preferir desplazarse a departamentos nuevos de renovación urbana. El Cuadro 6 muestra que el principal incentivo para la movilidad habitacional de los residentes es el precio que podría obtenerse de la venta o transacción de su actual inmueble. En este sentido, un 30\% de los encuestados se declara proclive a mudarse a otra vivienda solo si le ofrecieran un muy buen precio por su actual residencia. En segundo lugar, otro incentivo poderoso es la posibilidad de obtener algún subsidio estatal, beneficio que motivaría a un 14\% de los actuales habitantes a inclinarse por la opción de buscar otra vivienda. Entre quienes dicen preferir cambiarse de casa, las alternativas son variadas: un $17 \%$ optaría por buscar una vivienda en la misma comuna, un $12 \%$ buscaría vivienda en comunas cercanas, mientras que un $15 \%$ se cambiaría a otra vivienda sin importar en qué comuna.

Las zonas Centro y Norte son las que tienen un porcentaje más alto de residentes que estarían dispuestos a cambiarse de vivienda, independientemente o no de que se cumplan determinadas condiciones. Por el contrario, los habitantes de las zonas Centro y Oriente son los que muestran mayor disposición a no cambiarse de residencia bajo ningún supuesto. En el caso de la zona Oriente, es claro que las cualidades urbanas preexistentes y la valoración positiva percibida acerca del cambio urbano generado por la aparición de la edificación en altura son factores gravitantes. 
Sin embargo, la ambivalencia de la zona Centro es bastante llamativa. Los resultados estarían indicando que las afectaciones ambientales generadas por la concentrada edificación en altura, y la ampliamente negativa percepción de mejoramiento de aportes públicos y privados que tal tendencia acarrea en la zona central, podrían ser factores gravitantes al momento de aspirar a un cambio rápido de vivienda para una población que ya se encuentra afectada por la intensificación de la construcción en altura en su entorno. Por otra parte, la resistencia al cambio de vivienda para población residente que no valora positivamente la renovación urbana podría explicarse por el muy importante atributo de valoración de la centralidad y cercanía a servicios (factor destacado en un 29\% de los casos en la zona Centro) para desear permanecer.

Otra posible explicación de esta alta disposición a mantener la residencia actual a cualquier costo es que un $85 \%$ de los encuestados/as señala las casas como la tipología de vivienda preferida, contra un $15 \%$ de preferencia por departamentos, siendo que el mercado en áreas centrales y pericentrales casi no ha ofertado viviendas aisladas o en baja altura en los últimos años. Es decir, el optar por relocalización en casas, factiblemente significa hacerlo por una oferta periférica o en el barrio alto, lo que resulta impracticable, por las razones económicas y/o de pérdida de centralidad ya explicadas.

CUADro 6 | Proyección de los habitantes respecto a su lugar de residencia para los próximos cinco años

\begin{tabular}{|l|c|c|c|c|}
\cline { 2 - 5 } \multicolumn{1}{l|}{} & CENTRO & $\begin{array}{c}\text { NORTE } \\
\text { (RECOLETA })\end{array}$ & ORIENTE & SUR \\
\hline Le interesa mucho cambiarse de casa & $13,3 \%$ & $14,0 \%$ & $8,1 \%$ & $9,9 \%$ \\
\hline $\begin{array}{l}\text { Le interesaría cambiarse pero necesitaría un } \\
\text { subsidio }\end{array}$ & $15,8 \%$ & $14,0 \%$ & $9,9 \%$ & $9,2 \%$ \\
\hline $\begin{array}{l}\text { Le interesaría cambiarse de casa solo si es } \\
\text { que le ofrecieran un MuY buen precio }\end{array}$ & $26,0 \%$ & $29,8 \%$ & $34,2 \%$ & $39,7 \%$ \\
\hline $\begin{array}{l}\text { No le interesa cambiarse de casa ni barrio de } \\
\text { ninguna forma }\end{array}$ & $41,3 \%$ & $33,1 \%$ & $42,9 \%$ & $34,4 \%$ \\
\hline NS/NR & $3,6 \%$ & $9,1 \%$ & $4,9 \%$ & $6,8 \%$ \\
\hline Total & $100 \%$ & $100 \%$ & $100 \%$ & $100 \%$ \\
\hline
\end{tabular}

FUENTE ELABORACIÓN PROPIA

En el caso eventual de mudarse (Gráfico 8), y en cuanto a la disyuntiva entre una vivienda nueva o una usada, las preferencias se reparten, observándose un 53\% a favor de opciones de vivienda usada y un $47 \%$ que priorizaría el acceso a una vivienda nueva, donde probablemente priman aspectos de calidad de construcción y tamaños de vivienda mayores usualmente asociados a la vivienda usada. La opción compra es evidentemente muy mayoritaria (90\%), tratándose en su mayoría de residentes que ya son propietarios y que valoran el actual precio de su propiedad al momento de pedirles situarse en un escenario de venta de esta. Sin embargo, aparece con fuerza nuevamente la opción que valora la localización central por sobre el tamańo de la vivienda, con un 71\% que preferiría un menor tamańo siempre y cuando la localización sea buena. 
GRÁfICo 8 | Preferencias habitacionales en caso de cambiarse

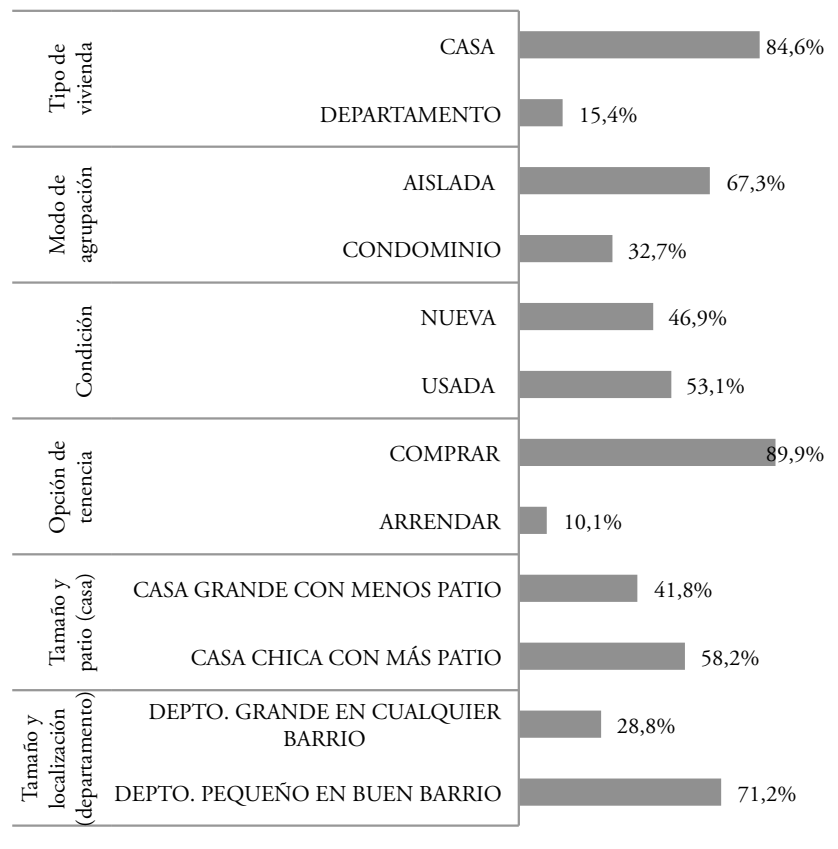

FUENTE ELABORACIÓN PROPIA

Asimismo, entre quienes se inclinan por una comuna de preferencia para residir, Núñoa es la que recoge el mayor porcentaje de menciones (25\%), seguida por Santiago (18\%), alguna comuna fuera del Área Metropolitana del Gran Santiago (13\%) y Providencia (12\%). Por otro lado, cabe hacer notar que entre las comunas que recogen más de un 3\% de menciones, no figura ninguna de localización periférica metropolitana, lo que reforzaría un perfil de opciones residenciales enfocado primariamente en comunas centrales y pericentrales al interior de Santiago y, secundariamente, en comunas extrametropolitanas que se visualizan como ofreciendo una mayor calidad de vida asociada a la menor densidad.

\section{Síntesis de resultados y discusión final}

Debe atenderse que el nivel socioeconómico (y socioocupacional) de los residentes comporta patrones disímiles según zonas. Mientras en las zonas Oriente y Sur son profesionales universitarios, en las zonas Norte y Poniente los jefes/as de hogar tienen baja escolaridad y hay una elevada concentración de personas que cursaron solo hasta el nivel de enseñanza media. El análisis de ingresos de hogares declarados sitúa los casos de Quinta Normal, Santiago y Recoleta-Independencia como los más bajos, con $37 \%$, 45\% y 49\% de población por sobre el límite de tres sueldos mínimos, mientras que los más altos son Macul y, sobre todo, Nuuñoa, confirmando con claridad las diferencias socioeconómicas de la población original residente en 
estas zonas. Esta diferenciación es importante al momento de considerar el "peso" relativo mayor que tiene el factor renta de suelo en las posibilidades económicas de los propietarios residentes originales de las zonas pericentrales Centro, Norte y Poniente, al momento de optar por una vivienda de reemplazo.

Los barrios analizados son valorados por los vecinos por su localización central, no por la supuesta "modernización” que traería la renovación. Entre los aspectos más valorados actualmente destacan las ventajas de localización, con mayor accesibilidad relativa a servicios y transporte. Por el contrario, existe un balance negativo de los efectos de la renovación urbana, por los márgenes bajos de renta de suelo que se obtendrían como compensación por la venta de las viviendas. Esta imagen se opone a la mayoritaria expectativa de los residentes de conseguir precios de venta altos (que además, paradójicamente, se contrapone a una valoración negativa generalizada acerca de la llegada de edificios en altura en sus barrios). Consultando por eventuales mejoras de estándares de servicios producto de la llegada de hogares de mayores ingresos vía edificios, entre los residentes originales se percibe un mayor impacto de bienes privados, pero no mejoras de equipamientos colectivos públicos (no pagos). Ello indica que el proceso de renovación genera cambios socioeconómicos que favorecen la venta de viviendas y plusvalías inmobiliarias, por los atributos de localización y conectividad propios de estas viviendas en la ciudad. Y a la vez, genera mejoras de servicios de bienes privados, como restaurantes y comercios, aunque ellos no significan más facilidades de deporte, colegios ni salud para las áreas de influencia, manteniéndose estos equipamientos anclados en el cono de alta renta y suburbios de ingresos medios de la metrópoli.

La renovación urbana en altura se vende en Santiago como "calidad de vida" por los desarrolladores, modelo de redesarrollo que también ha encontrado justificación al ser presentado como antítesis de la expansión urbana histórica, la cual implica alto consumo de suelo periurbano de la metrópoli. Sin embargo, para los vecinos antiguos centrales, la calidad de vida en sus barrios tiende a disminuir. Como se plantea más arriba, para los encuestados, la nota promedio asignada a la calidad de vida de sus barrios con anterioridad a la llegada de edificios en altura es de un 6,0 , mientras que la nota con que califican la situación actual de sus barrios apenas alcanza a un valor promedio de 4,8. Asimismo, la conformación de un escenario proclive a la presión al desplazamiento de sectores medio-bajos de estos barrios se advierte claramente en que más de un tercio de los vecinos ha sido contactado por inmobiliarias, o afectado por el mercado inmobiliario que ha comprado suelo dentro de la misma manzana, configurando esto último un escenario de presión por venta que puede redundar en un precio de pago por suelo desfavorable.

Pensando en un horizonte de futuro de cinco años, más de la mitad de los residentes de estas zonas expresa su intención de seguir ocupando su vivienda actual. Ante la eventualidad de vender y mudarse, el principal incentivo para la movilidad habitacional es el precio que podría obtenerse de la venta o transacción de su actual inmueble y un eventual subsidio estatal para hacerlo. Las condiciones de plusvalía y precios elevados de vivienda hoy en Chile son determinantes. Las zonas en las comunas de Santiago Centro, Recoleta e Independencia son las que tienen un porcentaje más alto de residentes que estarían dispuestos a cambiarse de vivienda 
bajo algunos supuestos de financiamiento externo y/o subsidios públicos, mientras que nuevamente son los habitantes de la comuna de Santiago Centro, sumados a los de Nuńoa, los que muestran mayor disposición a no cambiarse de residencia bajo ningún supuesto. Aparece con mucha fuerza la opción que valora localización central por sobre tamaño de la vivienda de reemplazo. Los residentes actuales saben que el factor suelo y localización es un activo de alto valor que debe ser compensado en el precio de mercado, y aspiran a que ello ocurra al momento eventual de tener que vender.

Sin embargo, buena parte de los hogares que eventualmente estarían dispuestos a vender su propiedad no podrían relocalizarse en las nuevas viviendas que ofrece el mercado inmobiliario en las mismas zonas. Esto es lo que se ha conceptualizado como "desplazamiento por exclusión de mercado", y que se expresa en las tasas de desplazamiento "T". Las estimaciones de este estudio muestran que algo menos de la mitad de los propietarios-residentes encuestados no obtendrían tasas iguales o mayores que 1 , y se verían así imposibilitados de alcanzar a costear, con la renta obtenida de su propiedad, el departamento requerido en la misma zona de renovación para alojar su hogar. Esto refleja un proceso donde el encarecimiento de los departamentos ofertados en estas zonas hace insuficiente incluso la venta de predios para costearlos. Se trata de un ciclo de reemplazo de la vivienda que a los actuales residentes de las zonas de renovación estudiadas no les permite sostener la misma localización. Ello apoya la hipótesis de que el modelo de verticalización residencial de las zonas centrales del AMGs, con incrementos muy puntuales de densidad, no implica el fin del patrón histórico de suburbanización, sino que genera una tasa considerable de expulsión de residentes hacia afuera de esos mercados, alimenta también un proceso continuo de periferización de residentes de bajos ingresos y, por ende, recompone la estructura socioespacial de la metrópoli.

Una pregunta que surge es acerca de la necesidad de política pública e investigación que arroja el proceso estudiado, que solo ha sido posible por la existencia de un entorno de políticas locales que han priorizado dar facilidades al mercado, sin regularlo ni exigirles a sus operadores impactos mejores sobre el entorno. Así, las expectativas de ganancia por explotación de la renta de suelo, y un Estado que ha sido de muchas formas contemplativo, explican la extremadamente alta densidad y disminuido tamaño de los departamentos ofertados, y la congestión en el uso del equipamiento existente. Claramente deben estudiarse las demandas de ampliación del equipamiento que induce la renovación -sea de densidad alta, media o bajay asegurar los aportes necesarios para el desarrollo de equipamientos colectivos con fondos de los proyectos nuevos. Las demandas de inversión en mantención de los espacios públicos próximos a los proyectos deben discutirse, ya sea como operaciones integrales de los proyectos privados (articulando morfológicamente el espacio público con las edificaciones y coordinado con programas público-privados de revitalización comercial similares a los modelos de Town Centre Management; véase, por ejemplo Coca-Stefaniak, Parker, Quin, Rinaldi \& Byrom, 2009 para una revisión comprehensiva de casos europeos), o como derivados de un proceso más amplio de implementación de políticas e instrumentos de captura de plusvalía para desarrollo urbano público (Smolka, 2013). 
Previo a este estudio, el interés de investigación sobre procesos de reestructuración social y residencial en zonas centrales había sido mayoritariamente enfocado a describir, catalogar y explicar las características de los residentes nuevos, dejando de lado el importante rol que cumplen los residentes propietarios antiguos al momento de vender sus propiedades al mercado inmobiliario, capitalizar renta de suelo y percibir las transformaciones ocurridas en sus entornos urbanos inmediatos. Incluso se debate en Chile sobre la existencia de procesos de gentrificación en el centro y pericentro de Santiago, con opiniones centradas exclusivamente en el análisis de residentes nuevos, sin considerar el necesario análisis en profundidad de las características socioeconómicas y culturales, así como las percepciones y preferencias de localización, de los residentes antiguos.

En el plano de la investigación futura, debería tomarse como opción montar observatorios de calidad de vida por vecinos nuevos y antiguos, y prestar atención a su evolución y al entorno de economía inmobiliaria que la determina en períodos largos, ya que -como se aprecia en los resultados de este estudio- los procesos de recambio inmobiliario y demográfico a los cuales se puede hacer seguimiento son de largo plazo (más de una década). Asimismo, deben generarse indicadores válidos y comprensibles de las rentas de suelo realmente capturadas tanto por los desarrolladores como por los vecinos antiguos (una forma podría ser transparentar y publicar regularmente datos de compraventa de suelo del Conservador de Bienes Raíces), junto con avanzar hacia estudios integrales con indagaciones cualitativas profundas acerca de las percepciones y aspiraciones de vida urbana y localización por parte de los residentes antiguos de los barrios que se renuevan en altura.

\section{Referencias bibliográficas}

Aalbers, M. (2011). Place, exclusion and mortgage markets. Malden, MA: Wiley-Blackwell.

Arriagada, C., Moreno, J. \& Cartier, E. (2007). Evaluación de impacto del Subsidio de Renovación Urbana en el Área Metropolitana de Santiago (1991-2006). Santiago: Ministerio de Vivienda y Urbanismo, División de Estudios, Serie viI. Disponible en http://www. minvu. cl/opensite_20070411164455. aspx

Borsdorf, A. \& Hidalgo, R. (2013). Revitalization and tugurization in the historical centre of Santiago de Chile. Cities, (31), 96-104. http://dx.doi.org/10.1016/j.cities.2012.09.005

Clark, E. (1988). The rent gap and transformation of the built environment: Case studies in Malmö 1860-1985. Geografiska Annaler, Series B, Human Geography, 70(2), 241-254. doi: $10.2307 / 490951$

Coca-Stefaniak, J., Parker C., Quin, S., Rinaldi, R. \& Byrom, J. (2009). Town centre management models: A European perspective. Cities, 26(2), 74-80. http://dx.doi. org/10.1016/j.cities.2008.12.001

Contreras, Y. (2011). La recuperación urbana y residencial del centro de Santiago: Nuevos habitantes, cambios socioespaciales significativos. EURE, 37(112), 89-113. Disponible en http://www.scielo.cl/pdf/eure/v37n112/art05.pdf 
Harvey, D. (1990). Los límites del capitalismo y la teoría marxista. México, D.F.: Fondo de Cultura Económica.

Instituto Nacional de Estadísticas (INE), Chile. (2003, marzo). Censo 2002. Sintesis de resultados [online]. En http://www.ine.cl/cd2002/sintesiscensal.pdf

Inzulza-Contardo, J. (2012). "Latino-gentrification"? Focusing on physical and socioeconomic patterns of change in Latin American inner cities. Urban Studies, 49(10), 2085-2107. doi: 10.1177/0042098011423425

Jaramillo, S. (2009). Hacia una teoría de la renta del suelo urbano (2a ed.). Bogotá: Centro de Estudios sobre Desarrollo Económico (CEDE), Universidad de Los Andes.

López-Morales, E., Gasic, I. \& Meza, D. (2012). Urbanismo pro-empresarial en Chile: políticas y planificación de la producción residencial en altura en el pericentro del Gran Santiago. Revista INVI, 27(76), 75-114. http://dx.doi.org/10.4067/S0718-83582012000300003

Schlack, E. \& Turnbull, N. (2011). La colonización de barrios céntricos por artistas. Revista_180_ arquitectura_arte_diseño, (24). Disponible en http://www.revista180.udp.cl/ ediciones/24/colonizacion_24.htm

Slater, T. (2009). Missing Marcuse: On gentrification and displacement. CityAnalysis of Urban Trends Culture Theory Policy and Action, 13(2-3), 292-312. http://dx.doi.org/10.1080/13604810902982250

Smolka, M. (2013). Implementing value capture in Latin America: Policies and tools for urban development. Cambridge, ma: Lincoln Institute of Land Policy. 